\title{
Key technologies for construction of Jinping traffic tunnel with an extremely deep overburden and a high water pressure
}

\author{
Shougen CHEN*, Heng ZHANG, Xinrong TAN, Liang CHEN \\ School of Civil Engineering, Southwest Jiaotong University, Chengdu 610031, China
}

\begin{abstract}
Jinping traffic tunnel is one of the deepest traffic tunnels in the world with a maximum overburden of $2375 \mathrm{~m}$ and the overburden over $73 \%$ of its total length is larger than $1500 \mathrm{~m}$. The tunnel is $17.5 \mathrm{~km}$ long and designed to provide a shortcut road between two hydropower stations: Jinping I and Jinping II of the Jinping Hydropower Project, located on Yalong River, Liangshan State, Sichuan Province, China. The tunnel is so deep that building any shafts is impossible. The construction starts from both ends (east and west ends), and the construction length from the west end is $10 \mathrm{~km}$ with a blind heading. This paper deals with an overview of this project and analysis of the engineering features, as well as key technologies developed and applied during the construction, including geological prediction, rock burst prevention under a super high in-situ stress, sealing of groundwater with a high pressure and big flow rate, ventilation for a blind heading of $10 \mathrm{~km}$, wet spraying of shotcrete at zones of rock burst and rich water, etc. The application of the new technologies to the construction achieved a high quality tunnel within the contract period.
\end{abstract}

Key words: key technologies; Jinping traffic tunnel; extremely deep overburden; high water pressure

C 2011 JMT. All rights reserved.

\section{Introduction}

$\mathrm{T}$ he Jinping Hydropower Project is built at the Jinping big river bay of Yalong River from Kala to Jiangkou, the junction of three counties: Yanyuan, Mianning, and Jiulong, Liangshan State, Sichuan Province, China (Fig. 1). It is the fourth largest hydropower station in China with a total capacity of $8.4 \mathrm{MkW}$, only next to the Three Gorge (22.4 MkW), Xiluodu (12.6 MkW) and Baihetan (12 MkW) [1]. The Jinping Hydropower Project construction started in 2004 and is expected to be completed in 2015. The total cost of the project is about 45 billion $\mathrm{CNY}$.

The Jinping Hydropower Project consists of two hydropower stations: namely Jinping I and Jinping II [2]. Jinping $I$ is at the upstream of the river with a capacity of $3.6 \mathrm{MkW}$, and Jinping II is at the downstream with a capacity of $4.8 \mathrm{MkW}$. Jinping II is the biggest hydropower station among 21 stations on the Yalong River with the highest dam of $305 \mathrm{~m}$ in the world. The two hydropower stations are separated $18 \mathrm{~km}$ in distance by

\footnotetext{
Received Mar. 13, 2011; revision accepted May 9, 2011

${ }^{*}$ Corresponding author. Tel.: +86-13881941886

E-mail: csgchen2006@163.com (S.G. CHEN)

doi: 10.3969/j.issn.2095-087X.2011.02.004
}

the Jinping Mountain (more than $3000 \mathrm{~m}$ in altitude), and the existing road traffic in between travels about $150 \mathrm{~km}$ along the Yalong River with very poor conditions. To greatly improve the driving condition between the two stations, a tunnel namely Jinping traffic tunnel through the Jinping Mountain was constructed (Fig. 2).

The Jinping traffic tunnel consists of two parallel tunnels (Line $A$ and Line $B$ ) with a separation of $35 \mathrm{~m}$ [3]. Line $A$ is $5.7-7.0 \mathrm{~m}$ wide and $5.764-7.483 \mathrm{~m}$ high with section areas of $33.9-48.5 \mathrm{~m}^{2}$, while Line $B$ is $6.2-$ $7.5 \mathrm{~m}$ wide and $6.7-8.126 \mathrm{~m}$ high with section areas of $39.6-55.5 \mathrm{~m}^{2}$. The tunnel is $17.5 \mathrm{~m}$ long and parallels to the four diversion tunnels of Jinping II (Fig. 3).

As the Jinping traffic tunnel is constructed prior to the diversion tunnels, it can provide valuable geological information data and site trials for the later construction of the diversion tunnels. The Jinping traffic tunnel is deeply buried with a maximum overburden of $2375 \mathrm{~m}$ and the overburden over $73 \%$ of its total length is larger than $1500 \mathrm{~m}$. Thus, building shafts in between is not realistic. Its construction started from two ends (east and west ends), and the construction from the west end is $10 \mathrm{~km}$ in length with a blind heading (the longest one in the world for drill and blast tunneling). Fig. 4 shows the entrance to the tunnel from the west end. The tunnel was constructed since January 2004 and completed in August 2008. The total cost of the tunnel is about 820 


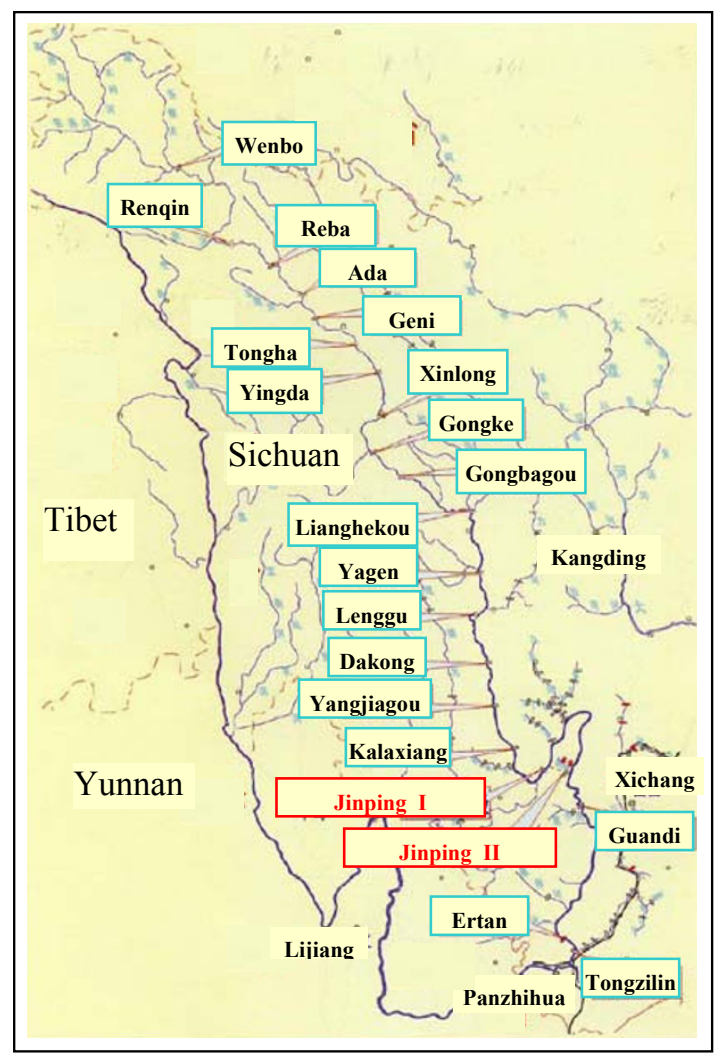

Fig. 121 stations on the Yalong River

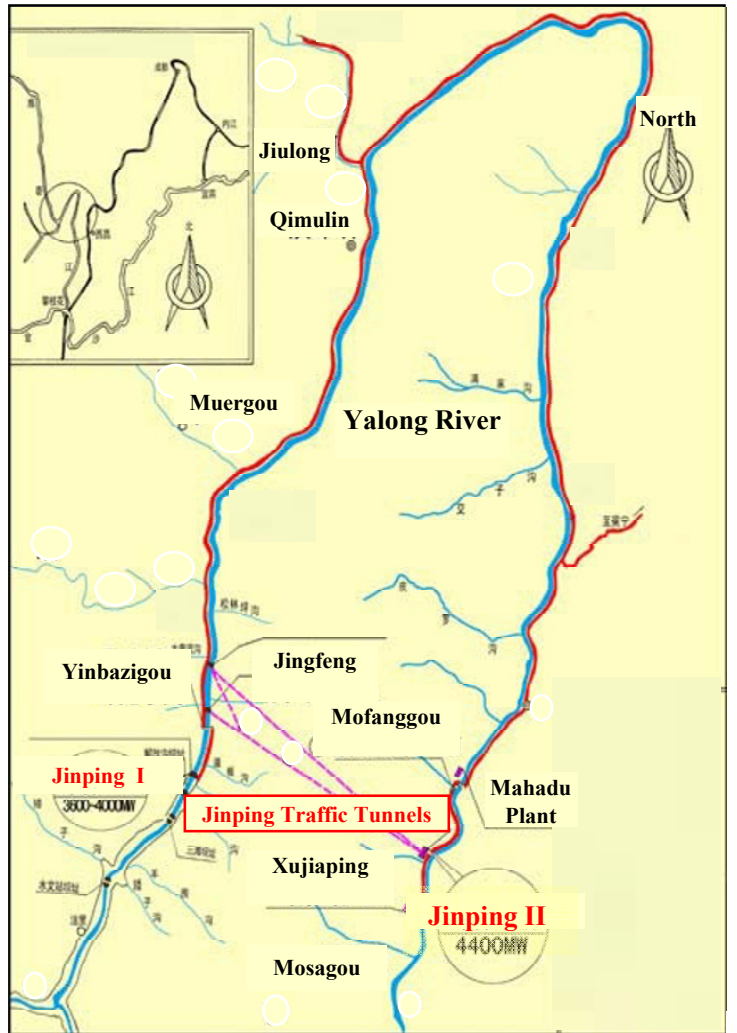

Fig. 2 Location of Jinping traffic tunnel

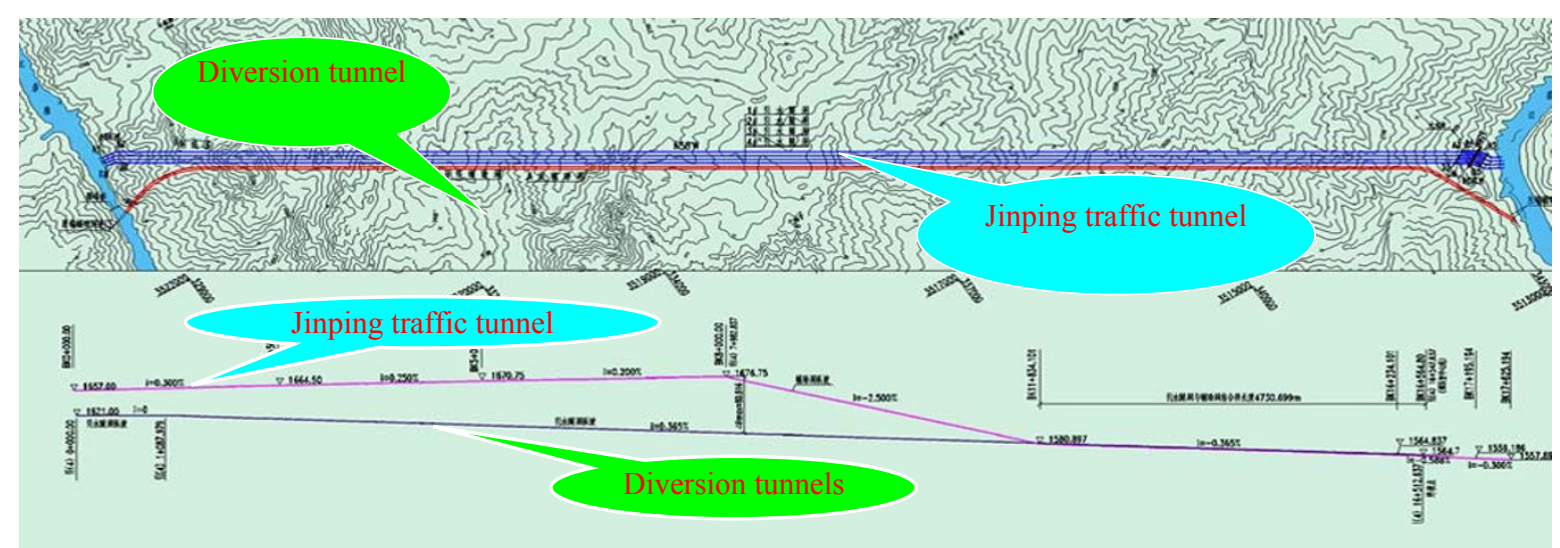

Fig. 3 Jinping traffic tunnel and diversion tunnels at Jinping II

million CNY while the west end costs 520 million CNY.

Jinping traffic tunnel is located in Karst area, mainly in Triassic system as shown in Fig. 5, while Carbonate rock (Marbles) covers about $70 \%-80 \%$ of the area including Triassic series (T1), Zagunao Formation (T2z), Baishan Formation (T2b), and Upper Triassic Series (T3). Due to extremely high in-situ stress, the region is heavily compressed with close composite folds in SN direction. The rock is basically solid with a uniaxial compressive strength (UCS) of 21.4-210 MPa and mostly classified as Grades II and III, while soft rock (phyllite and chlorite schist) covers only about $600 \mathrm{~m}$ in length.
Groundwater is very rich in this area, coming from rock fractures, Karst caves, underground rivers, etc. The tunnel bears a high groundwater head of about $1000 \mathrm{~m}$ with a maximum water pressure of up to $10 \mathrm{MPa}$ [4].

\section{Engineering features and construction challenges}

Jinping traffic tunnel is a super long tunnel with a high in-situ stress and high water pressure. The construction has encountered extremely difficult conditions and faced a number of challenges. 

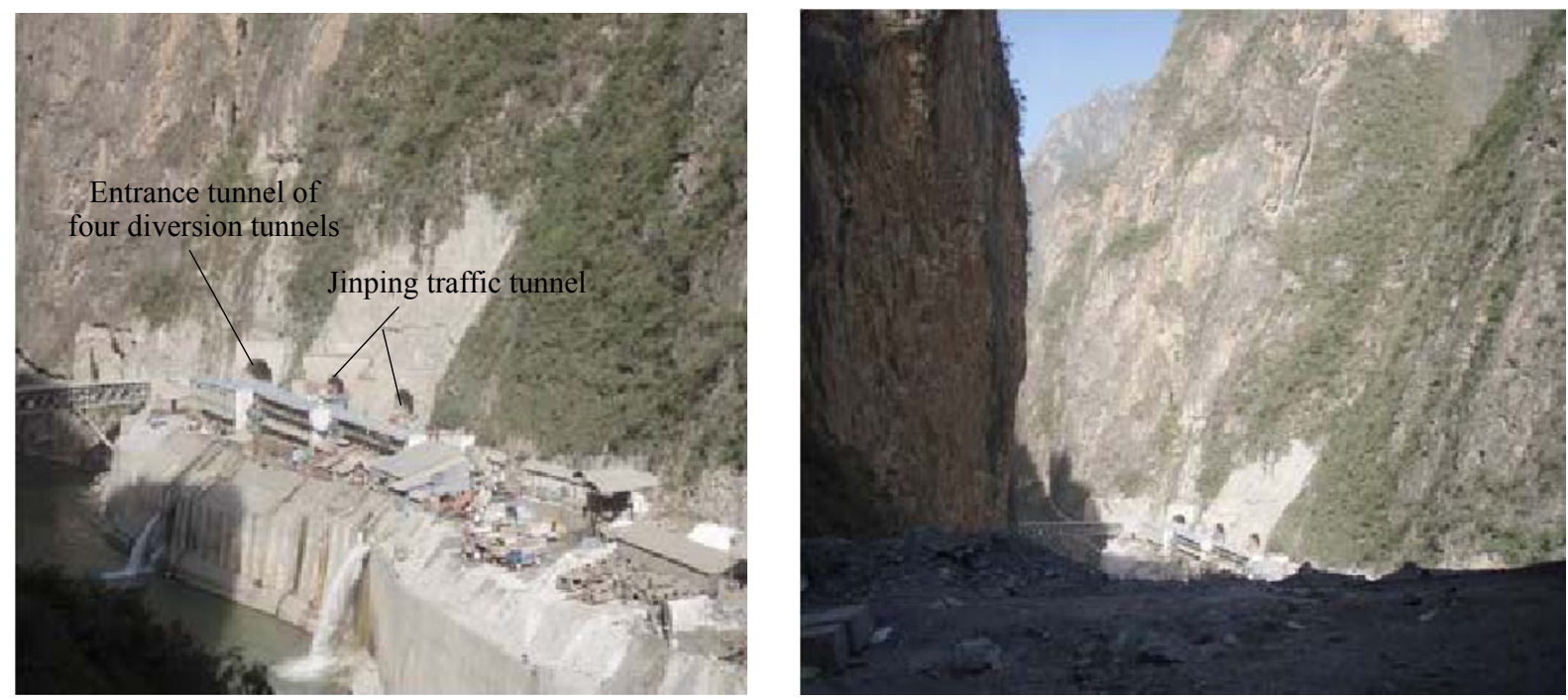

Fig. 4 Entrance to the west end of the tunnel

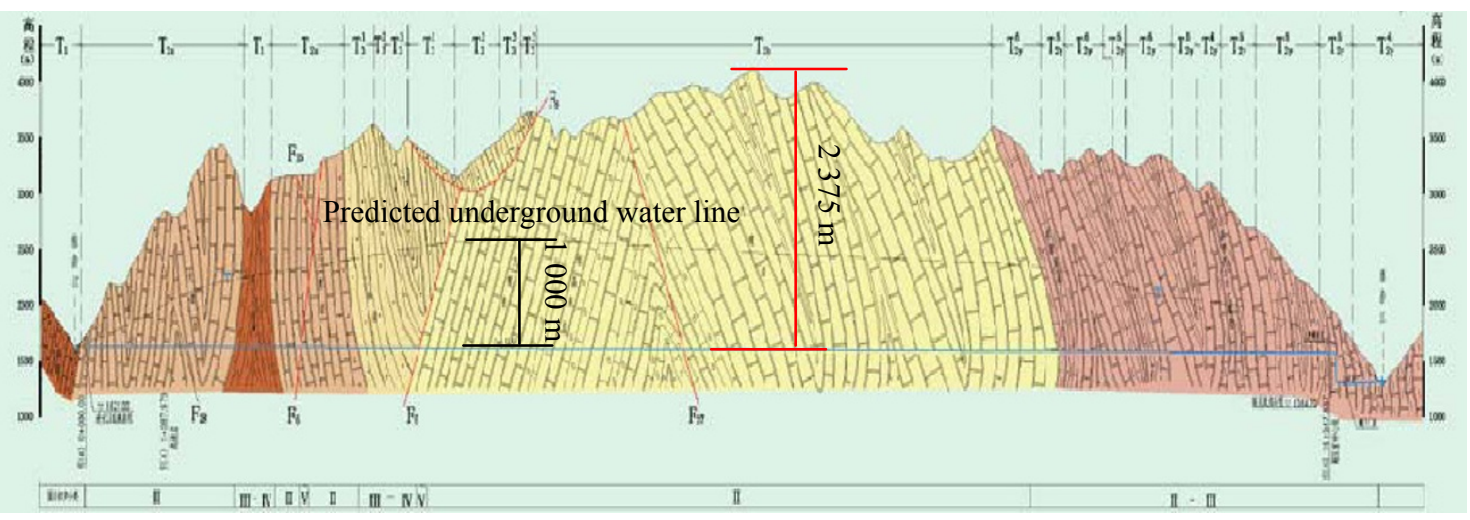

Fig. 5 Geological profile of Jinping traffic tunnel

First, the tunnel was planned to construct $10 \mathrm{~km}$ long from the west end in a blind heading. Given the limitations of the site condition, trackless transportation was adopted, which means that more smoke and dust would be generated during the transportation of stone slag. This was a significant challenge as for the ventilation design. Traditional ventilation of axial flow fans was suitable for the tunnel length less than $2 \mathrm{~km}$ and a blind heading tunneling. This was a large gap compared to the $10 \mathrm{~km}$ required. Therefore, new ventilation technologies must be developed.

Second, the large overburden of the deep tunnel generated a very high in-situ stress in hard rock, causing frequent strong rock bursts (Fig. 6). According to the on-site investigation, the in-situ stress measured at an overburden of $1350 \mathrm{~m}$ in the tunnel was $29.82 \mathrm{MPa}$ in the horizontal direction and $44.2 \mathrm{MPa}$ in the vertical direction. The vertical in-situ stress at an overburden of $2375 \mathrm{~m}$ was estimated to be $70.1 \mathrm{MPa}$. The rock was mostly Marble with a UCS of up to $210 \mathrm{MPa}$. The strength to stress ratio defined as rock UCS divided by the in-situ stress was between 1 and 3 in most sections. Thus, rock burst was prone to occurring.

Third, the deep tunnel is accompanied by a rich groundwater with a high pressure up to $10 \mathrm{MPa}$ and a large flow rate up to $15.6 \mathrm{~m}^{3} / \mathrm{s}$ (Fig. 7). Because a curtain grouting in front of the working face to exclude water outside the tunnel before the excavation would delay the whole project, to avoid the delay and take into account of good rock quality in overall, it was suggested to allow the water to flow into the tunnels first and then seal the water flow afterwards. The sealing of the groundwater with such high pressure and high flow rate was another challenge to the tunneling. New technologies for water sealing must be developed and applied.

Other challenges were also encountered, including that the tunnel cross section was small $\left(33-55 \mathrm{~m}^{2}\right)$ and the blind heading was long $(10 \mathrm{~km})$, which greatly restricted the use of large machinery. In the Baishan Formation (T2b), the water flow in the tunnel was not only strong, but also stable (Fig. 8). Moreover, one line must be used for water drainage, and another line for construction, 
which greatly slowed the tunneling advance. At rich water zones, drilling blasting holes and explosive charging were difficult. Thus, special operations must be adopted. Furthermore, the west end (10 km long) of Jinping traffic tunnel must be completed in 50 months, which required the average monthly advance of more than $200 \mathrm{~m}$.

Because of the engineering features above, the difficulties faced in the construction of Jinping traffic tunnel can be expected as follows: (1) advanced prediction of complex geological structure with rich water, (2) sealing of groundwater with a high pressure and big flow rate, (3) prevention of rock burst occurrence under super deep overburden and high in-situ stress, (4) ventilation over $10 \mathrm{~km}$ under trackless transport condition, (5) shotcrete spraying at strong to extremely strong rock burst zones, (6) shotcrete spraying at rich water zones, (7) machinery matching for super long tunnel construction, (8) blasting of uniform Marbles with high tensile strength, and (9) organization of multiple working procedures at rich water zones.
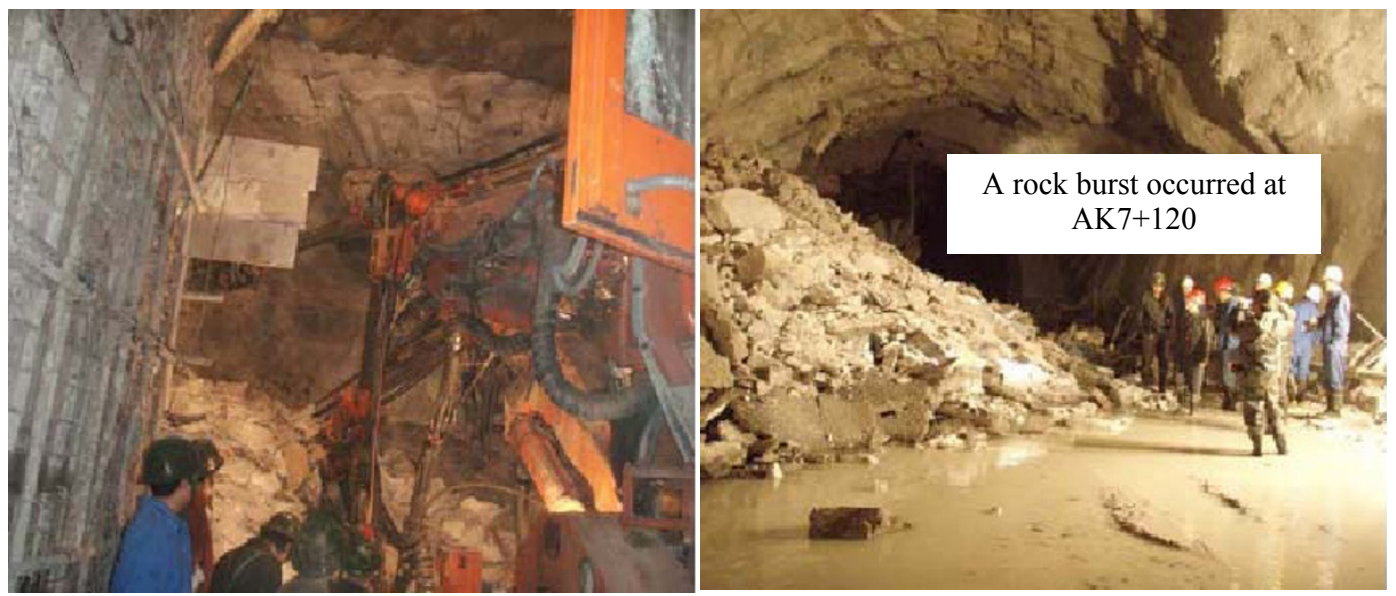

Fig. 6 Rock bursts during drilling

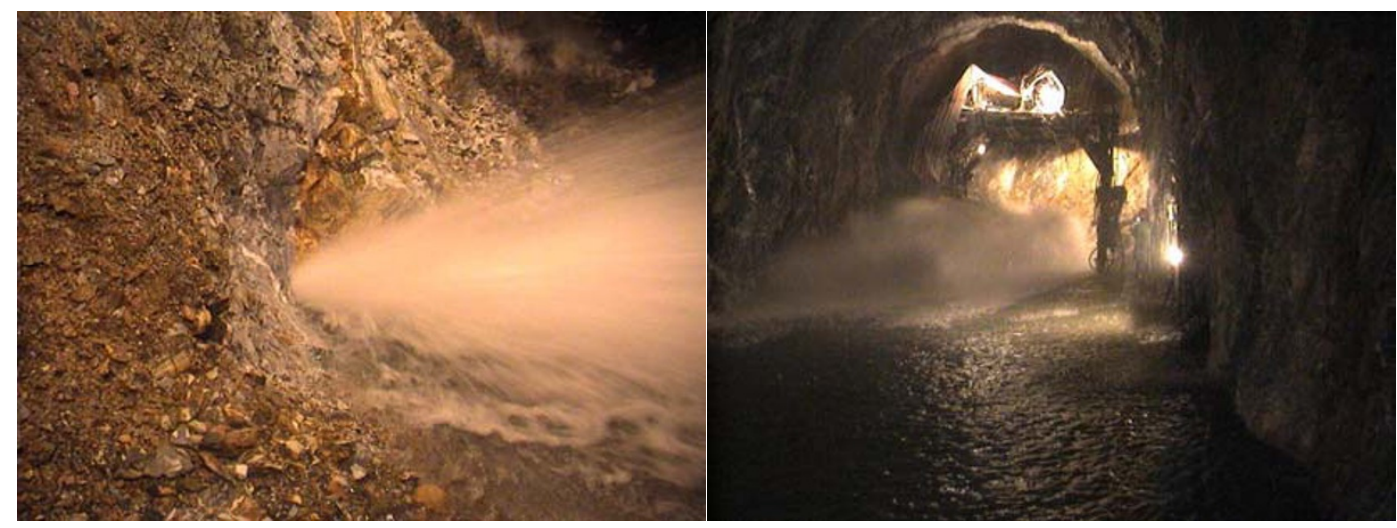

Fig. 7 Point water burst during the construction

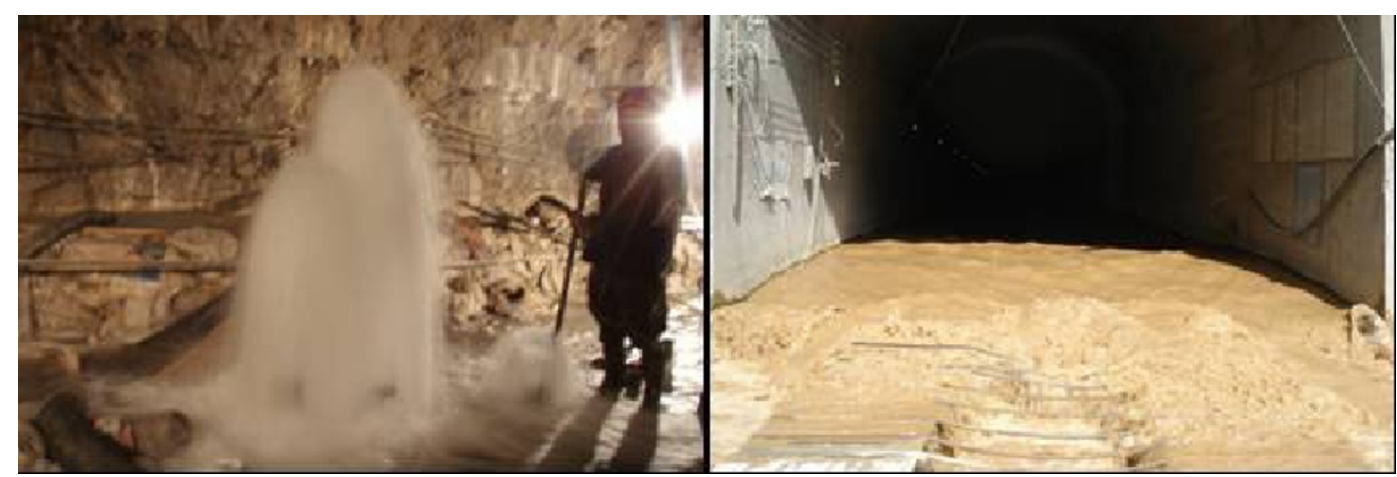

(a) Water inflow from the bottom

(b) Water flow at the entrance to the tunnel

Fig. 8 Rich water during the tunneling 
To overcome these difficulties encountered during the construction, key technologies were developed, including an integrated geological prediction system, sealing technology of groundwater with high pressure and big flow rate, rock burst prevention technology under a super high in-situ stress, ventilation technology for a blind heading of $10 \mathrm{~km}$, wet spraying technology of shotcrete at zones of rock burst and rich water.

\section{Geological prediction for guiding the construction}

Jinping traffic tunnel is located in a Karst area with a complex geological condition. Due to the high overburden, the site geological investigation before construction was limited and the geological prediction from the tunnel working face during the construction was required in order to provide a detailed geological description to guide the construction.

In order to increase the reliability of the geological prediction, an extensive literature review and a series of field tests were conducted. Particularly, new technologies of geophysical exploration were optimized by testing a total of nine geophysical exploration methods including TSP203, landsonar (LDS-1), surface radar (SIR20), transient electromagnetic method (TEM), beam method, electronic method, borehole radar, infrared exploration, and acoustic CT technique. From the field trials, it was found that TSP203 and landsonar methods can achieve similar results for large geological structures, while TSP203 can collect more information in a longer distance (up to $150 \mathrm{~m}$ ). The surface radar was more effective for Karst geology with a higher accuracy in a short distance (up to $30 \mathrm{~m}$ ). The electronic method and infrared exploration were more sensitive to water existence, and thus fit for ground water prediction, while the infrared exploration was more convenient and spent less time.

Based on the studies above, an integrated geological prediction system was established in terms of four phases: long, medium, short, and near terms, as shown in Fig. 9. The system was applied to the geological prediction at working face and involved as a major working procedure in the construction [5]. Three methods, including geological analysis, geophysical exploration, and borehole drilling were utilized at different phases in the system. The long-term prediction was to preliminarily estimate difficult geologies along the whole tunnel and make a plan for the medium-term prediction, by analyzing geological reports, performing surface survey, and exploring at key sections, etc. The medium-term prediction was to provide an early understanding of major geological difficulties up to $100-150 \mathrm{~m}$ in front of the working face, using TSP203 and landsonar methods.

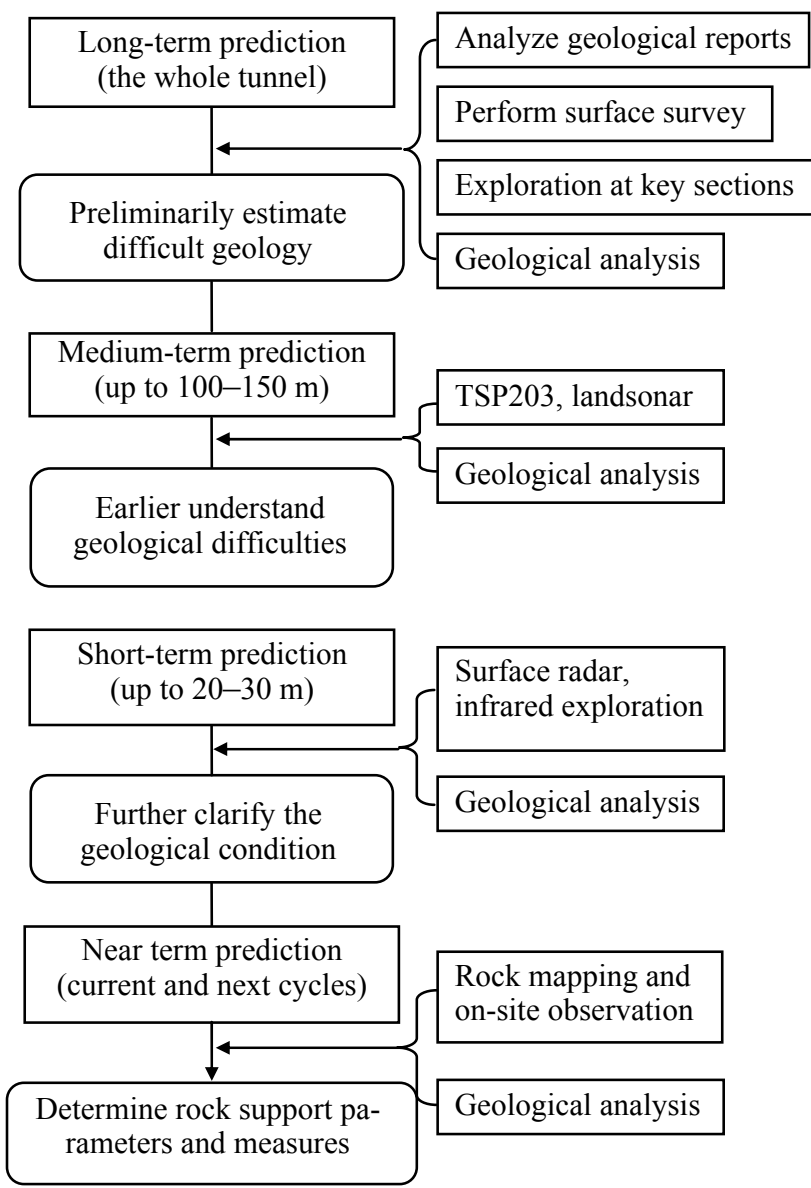

Fig. 9 An integrated system of geological prediction

The short-term prediction was to fully clarify the geology up to $20-30 \mathrm{~m}$ in front of the working face, using surface radar and infrared exploration. If necessary, borehole drilling and borehole radar could also be used. The near-term prediction was to describe a more specific geology for the current and next cycles, using rock mapping and site observation, in order to finally determine rock support parameters and measures to be taken. It should be noted that the geological analysis was very important in the geological prediction system and it is strongly suggested to have an experienced geological engineer in the geological prediction team.

By the use of the system, the geological prediction accuracy was greatly improved and a good result was obtained. A comparison between the geological prediction result and site observation record showed that the prediction accuracy reached more than $80 \%$ and that, more importantly, major difficult geological conditions were well predicted.

\section{Rock burst prevention under super high in-situ stress}

According to the statistical analysis for the first $8000 \mathrm{~m}$ excavation, the length with rock burst was 
$1731.2 \mathrm{~m}$ and $1535.9 \mathrm{~m}$, being $21.6 \%$ and $19.2 \%$ of the total length, in Lines $A$ and $B$, respectively. Compared to the rock burst classification for hydropower projects, the rock bursts occurred in the tunnel mostly ranged from medium to very strong extent, while very strong rock bursts occurred only at two sections of BK6+096-106 and BK6+723-755 (Fig. 6).

The rock burst features in the tunnel were observed on site: (1) most rock bursts occurred in Triassic system, especially in Zagunao Formation (T2z) and Baishan Formation (T2b), and some in Triassic series (T1) and Triassic upper series (T3). (2) Rock bursts mostly occurred at crown, bulging line and walls, and occasionally at working faces as well. (3) Rock bursts occurred when the overburden was higher than $860 \mathrm{~m}$, and became stronger with the increase in overburden. (4) Rock bursts strong to very strong were in a plate shape, and occurred in fine grain dolomitic massive marbles with UCS of 163-210 MPa near faults and beddings, particularly when the geological structures were parallel to the tunnel surface. The thickness of the rock plate was mostly $0.1-0.8 \mathrm{~m}$ and the maximum plate size was $0.8 \times 1.5 \times 3.2 \mathrm{~m}$. (5) Rock bursts lessened with water presence, which is consistent with normal realization. (6) Rock bursts occurred at 2-5 h after blasting and lasted for several days to half a month, but very strong rock bursts occurred at 5-20 h after blasting. (7) Rock bursts occurred within $2 D$ ( $D$ is the tunnel diameter) from the working face. From the site observation, it can be seen that besides the high in-situ stress and high rock strength, the geological structure is also a very important factor to induce bigger rock bursts. This could be due to the stress concentration near geological structures, even before the excavation.

Based on the site observation and analysis of influential factors, it can be understood that high strain energy gathering in hard rock induced by the high in-situ stress was the internal factor to cause rock bursts, and thus the key measure was to release the strain energy or reduce the energy release rate. Field tests showed that traditional rock burst prevention methods, including spraying water onto rock surface to soften rock, drilling holes into rock to release stress, forming a fractured zone around the tunnel in advance by blasting in deep holes, etc., were ineffective to release energy. A detailed analysis on the phenomenon showed that the in-situ stress was very high, and though using traditional methods can release energy, the energy release speed was much slower than the energy gathering speed. Therefore, effort must be made to achieve an energy releasing speed faster than the energy gathering speed.

A new rock support system for slowing the energy gathering speed was proposed in Ref. [6]. The system was made up of swellex bolt and high performance shotcrete with nano-admixture, based on the traditional supports of steel arch and reinforcement mesh. The swellex bolt is shown in Fig. 10 and the most advantage of the bolt lies in fast installation. Its installation needs only $2 \mathrm{~min}$, consuming $50 \%$ time compared to normal bolts. As shown in the figure, the bolt is originally a

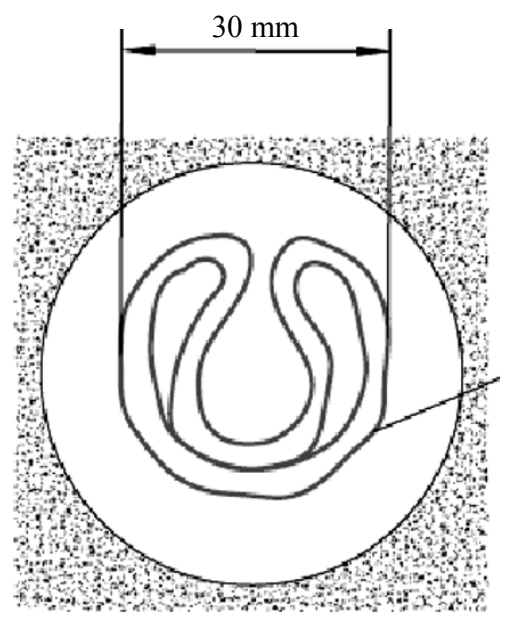

(a) Original bolt shape before swelling

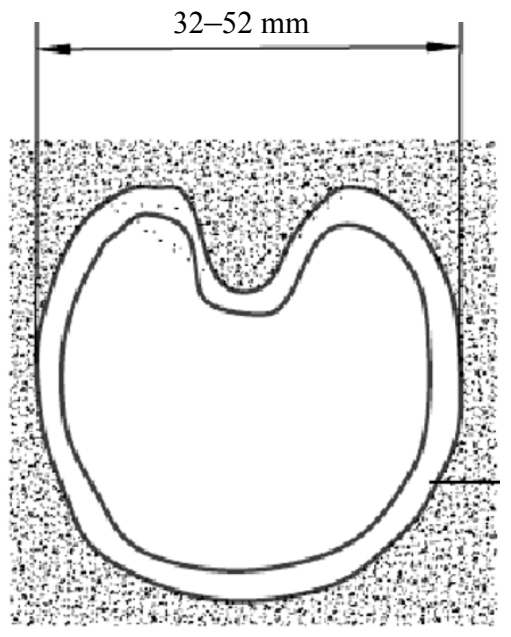

(b) Bolt shape after welling

Fig. 10 The swellex bolt support

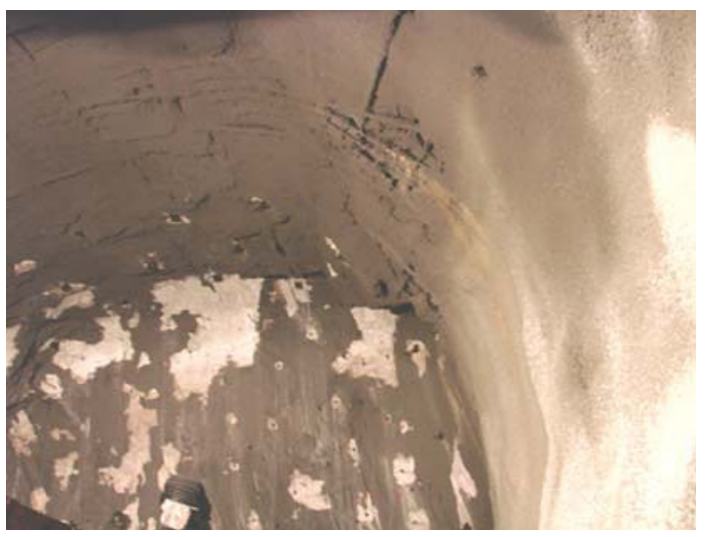

Fig. 11 Effect of swellex bolt and shotcrete with nano-admixture 
double concave in shape. When water was pressed with a pressure of about 4.0 MPa into the bolt, the bolt immediately swelled up and contacted with the borehole firmly to achieve a fast and strong support (Fig. 11).

The shotcrete with nano-admixture can quickly spray a much thicker (more than $10 \mathrm{~cm}$ ) and stronger support than normal shotcrete. By applying the support system, rock bursts in the tunneling were well controlled.

\section{Sealing of groundwater with high pres- sure and big flow rate}

Jinping traffic tunnel is located in Karst area, where soluble and insoluble rocks are distributed alternatively in parallel to the direction of main geological structures to form a groundwater network. The rock dissolution generates fractures, thick aperture, holes, caves, and even underground rivers. Water bursts will occur when a large water channel is revealed, or a local water stream near caves and faults is encountered, or at interfaces between soluble and insoluble rocks. In the construction, hundreds of faults were encountered, and 21 big faults became main water burst zones.

The groundwater was very rich with a very high pressure and big flow rate. Based on a statistical analysis on the water flow for the first $8000 \mathrm{~m}$ excavation (each $4000 \mathrm{~m}$ for Line $A$ and Line $B$ ) at Zagunao Formation $(\mathrm{T} 2 \mathrm{z})$, it was found that the ground water pressure ranged 6-10 $\mathrm{MPa}$ and the maximum instant water inflow was $15.6 \mathrm{~m}^{3} / \mathrm{s}$ at BK2+637. In Baishan Formation (T2b), a point water burst occurred with a maximum water inflow of $150 \mathrm{~L} / \mathrm{s}$ and a throwing distance up to $50 \mathrm{~m}$ at AK5+225 (Fig. 7). The length with rich water for the first $16 \mathrm{~km}$ excavation (each $8000 \mathrm{~m}$ for Line $A$ and Line $B$ ) was $3530 \mathrm{~m}$ for Line $A$ and $3519 \mathrm{~m}$ for Line $B, 44 \%$ of the total length.

The treatment of the groundwater experienced a difficult period during the construction. Through a longtime of field test, exploration and improvement, a sealing technology of groundwater with high pressure and big flow rate was formed. In the system, the integrated geological prediction system presented in earlier section was firstly applied to predicting the water existence in front of the working face in order to provide precise data to the groundwater sealing design. Second, based on the geological prediction information, some principles of groundwater treatment were executed. The principles are described as: (1) water treatment orders from easier ones to difficult ones, from crown, then walls and finally bottom; (2) water is guided before water sealing; (3) overall consideration must be taken in water treating since the water always comes from the weakest points; and, (4) making a comprehensive water treatment plan by taking into account geology and effect of initial support before sealing is most important.

The measures of water sealing in the tunneling can be summarized as follows [7]. The advanced grouting with deep holes in front of the working face was used only when groundwater with a very high pressure is found. A special valve was installed to stop water immediately if required. When the groundwater was revealed, sealing was done at two stages: surface sealing and then consolidation grouting. In the cases when the groundwater comes from dissolution fractures, holes and even caves, the sealing of groundwater was very difficult and traditional grouting was not applicable because of the high pressure and big water flow quantity. To overcome this problem, a new technology using mold bag and expansible hose was developed and applied. Both mold bag and expansible hose were almost the same despite that the mold bag was much larger than the expansible hose. Mold bags were used for sealing groundwater from bigger holes and caves, while expansible hose were used for sealing groundwater from fractures and smaller holes. The mold bag was made of nylon, polyester, or polypropylene and had a better permeability to allow water going through but remain cement. It was soft and became strong after consolidation (Figs. 12 and 13). Thus, it was especially suitable for sealing groundwater with high pressures and large water flow rates. Fig. 14 compares a tunnel section before and after water sealing. It can be seen that the sealing effect was a great success [8].

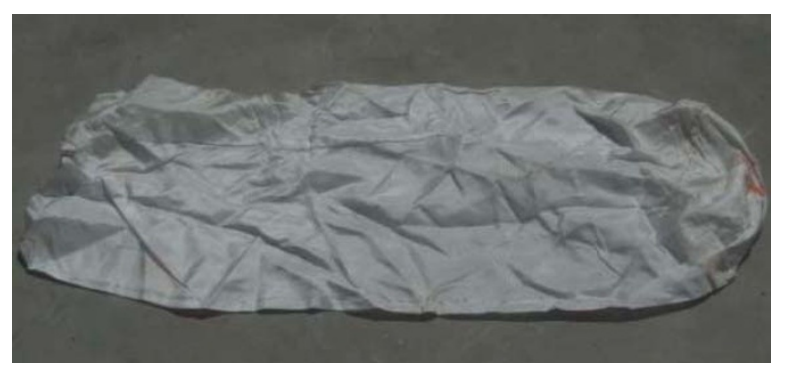

Fig. 12 Mold bag

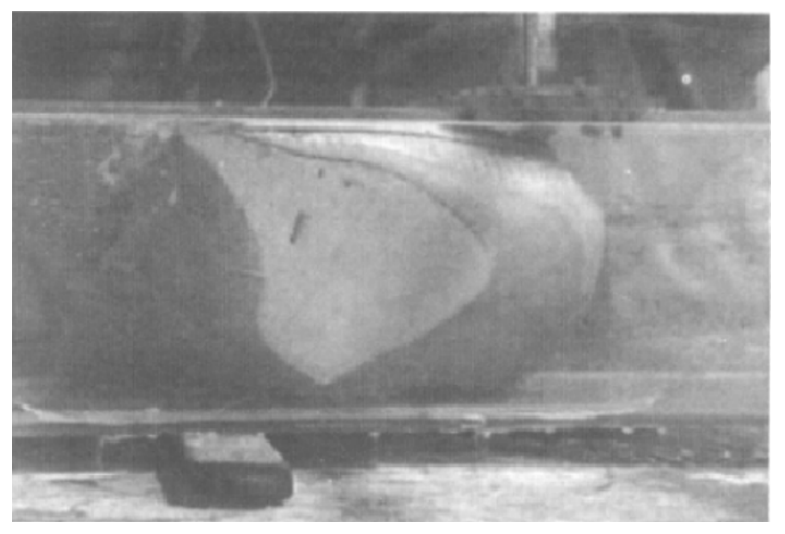

Fig. 13 Sealing effect of a mold bag 


\section{Ventilation for a blind heading of $10 \mathrm{~km}$}

According to the tunneling experience, trackless transportation was only applicable for the tunneling shorter than $1500 \mathrm{~m}$. The construction from west end of Jinping traffic tunnel was $10 \mathrm{~km}$ long and track transportation would be used. However, the entrance of the west end was too narrow to install track transportation system. Therefore, the trackless transportation was proposed for the tunneling, which means that more smoke and dust would be produced, causing the construction ventilation very difficult. The traditional tunneling ventilation using axial flow fans to send fresh air to the working face was applicable only for a blind heading of less than $2 \mathrm{~km}$. This was still a large gap from the requirement of the tunneling.

After analyzing the project features in a detail, a ventilation scheme was proposed by connecting the two parallel lines (Line $A$ and Line $B$ ) using connection channels between them. In the scheme, one line was used to send fresh air and the other to exhaust polluted air to form an air flow, as shown in Fig. 15. Jet fans with a great power were used to generate the air flow, while traditional axial flow fans were used only near working faces to send fresh air [9].

To optimize the ventilation design of the jet fans, numerical modeling using FLUENT and field trials was done [10]. The numerical modeling result validated this design conception and showed that using jet fans with a power of $75 \mathrm{~kW}$ and a separation of $500 \mathrm{~m}$ met the requirement of $10 \mathrm{~km}$ heading. The location of jet fans was also optimized and it was found that jet fans installed in the tunnel at 5-10 m close to connection tunnels at the upper stream can achieve a better ventilation result. Fig. 16 shows the $\mathrm{CO}$ concentration distribution at a section of $100 \mathrm{~m}$ from a jet fan for various installation heights. It can be seen that installing jet fans in a higher position is more effective.

\section{Wet spraying of shotcrete at zones of rock burst and rich water}

Because the rock mass in the tunnel was mostly good, and thus rockbolt and shotcrete were designed as permanent rock supports and no concrete lining was installed in most sections. However, field tests found that traditionally applying shotcrete at zones of rock burst and rich water was very difficult. At water-rich zones, the rock surface was wet and small water flows very often. Traditionally, it was not possible to directly apply shotcrete to the rock surface and required to seal water

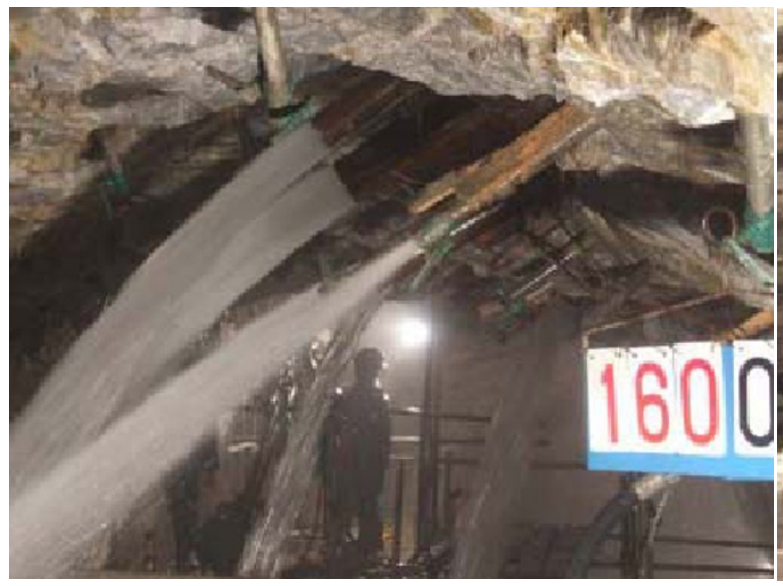

(a) Before sealing

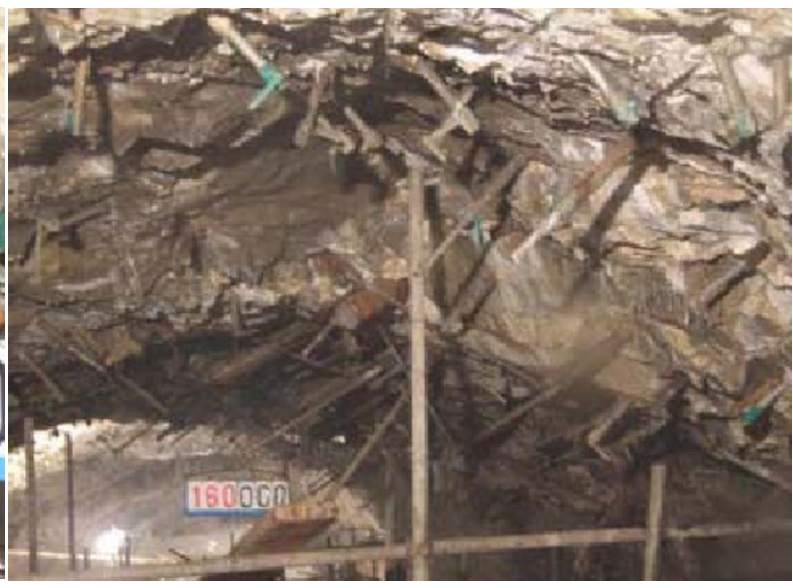

(b) After sealing

Fig. 14 Water sealing at BK5+160

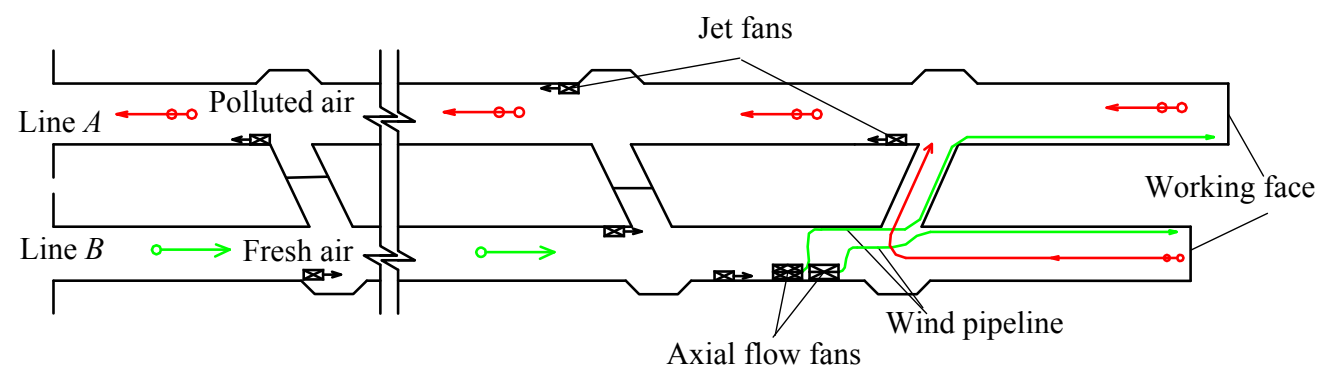

Fig. 15 Ventilation design using jet fans 


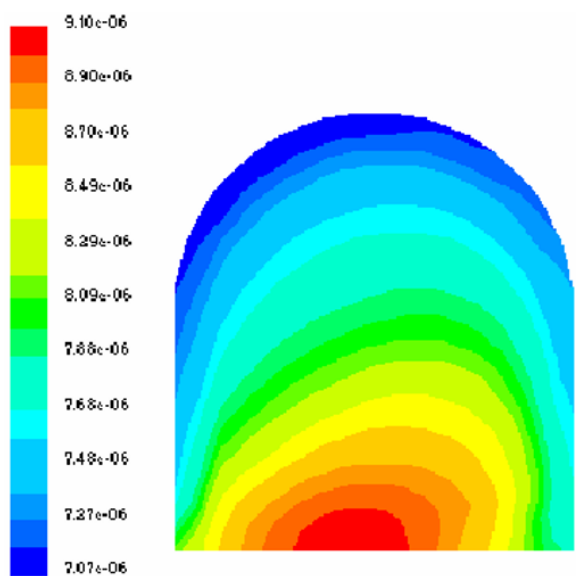

(a) Height of $1 \mathrm{~m}$

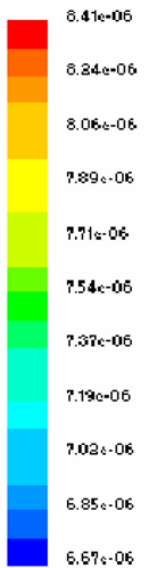

(c) Height of $3 \mathrm{~m}$
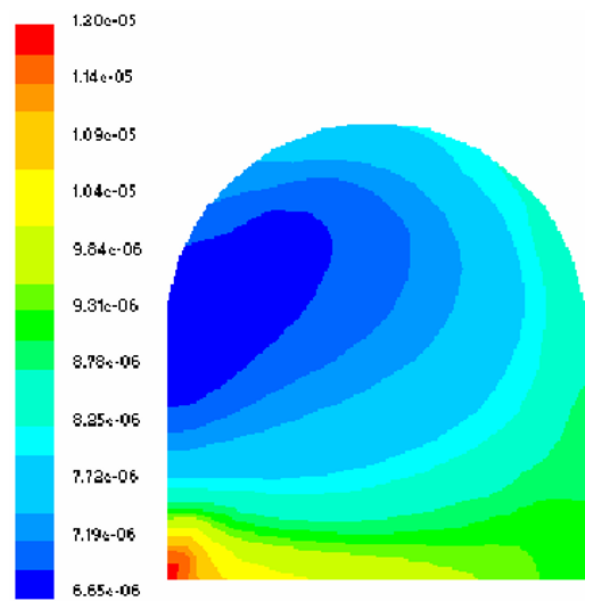

(b) Height of $2 \mathrm{~m}$

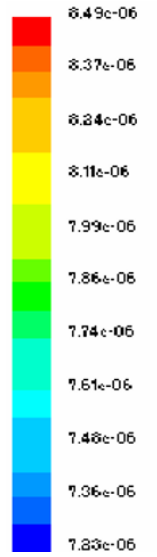

$7.350-06$

(d) Height of $4 \mathrm{~m}$

Fig. 16 Effect of installation height of jet fan

first before the spraying, which would delay the shotcrete support and cost more [3]. At rock burst zones, however, it required the shotcrete with a thick spraying and fast solidification to provide strong support as quick as possible [11]. Laboratory experiments and field tests were carried out to find a way to solve this problem. Based on the test results, a nano-admixture was produced

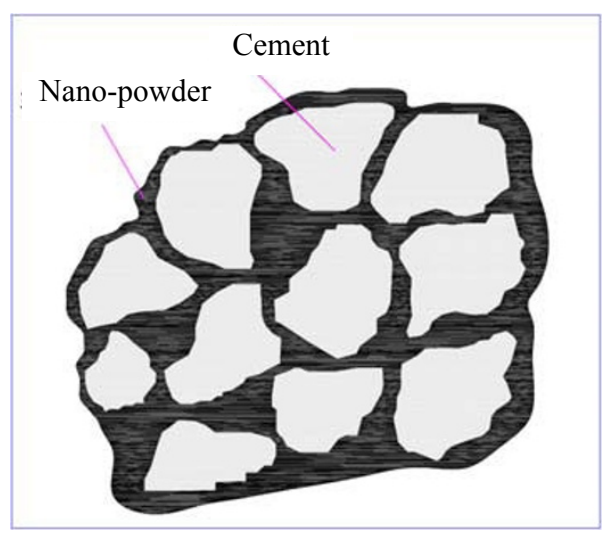

Fig. 17 Cementation between nano-powder and cement by grounding the zeolite to powder with a diameter less than $327.7 \times 10^{-9} \mathrm{~m}$. Fig. 17 shows the cementation between nano-powder and cement. By adding this admixture into shotcrete, we achieved wet spraying of shotcrete at zones of rock burst and rich water. Fig. 18 shows the effect of the wet spraying of shotcrete in a water-rich zone.

\section{Conclusions}

Based on the analysis of the engineering features and potential challenges faced, new technologies were developed and applied to the construction of Jinping traffic tunnel.

- An integrated geological prediction system was established in four phases: long term, medium term, short term and near term. Three methods, including geological analysis, geophysical exploration, and borehole drilling, were utilized at different phases in the system. It effectively predicted the geological condition in front of the working face. 


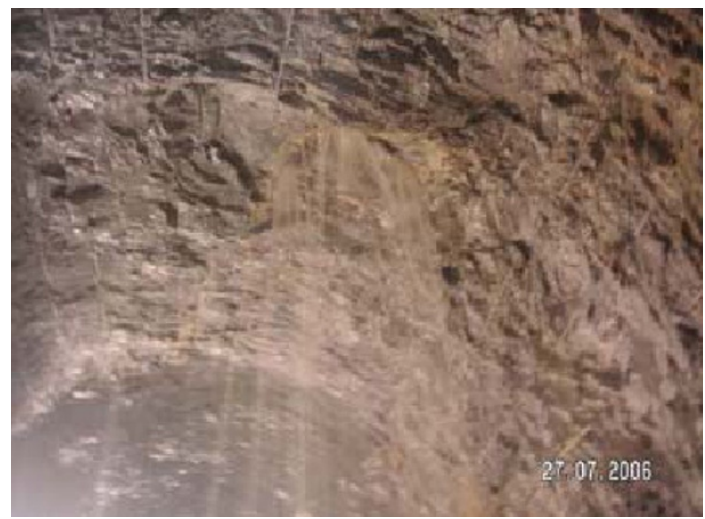

(a) Before shotcrete

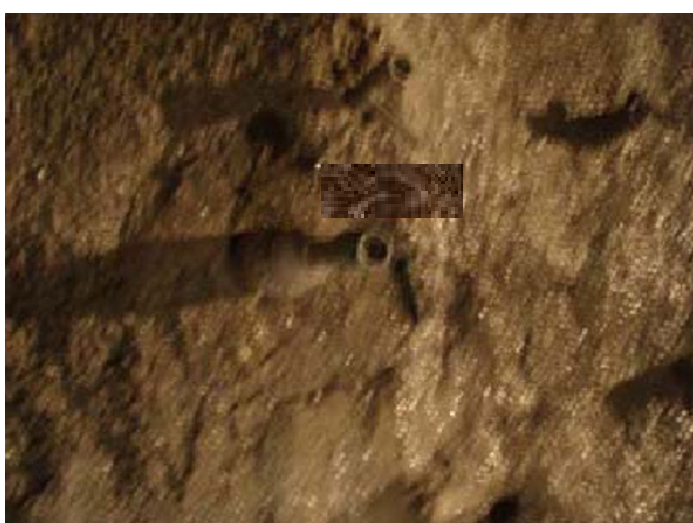

(b) After shotcrete

Fig. 18 Effect of shotcrete with nano-admixture

- The high strain energy gathering in hard rock induced by the high in-situ stress was the internal factor causing rock bursts in the tunneling. A technology of rock burst control was proposed using traditional methods to release the strain energy, and water swelling bolts and high performance shotcrete with nano-admixture were used to reduce the energy release speed. The technology controlled the rock bursts very well in the construction.

- Based on a longtime of field test, exploration, and improvement, a sealing technology of groundwater with a high pressure and large flow rate at water-rich zone was developed. Mold bags and expansible hoses were developed and applied with good results.

- Trackless transportation was proposed for the tunneling with $10 \mathrm{~km}$ blind heading. Based on a detailed analysis on the engineering features, a ventilation scheme was proposed, in which jet fans with high power were used to generate the air flow, while traditional axial flow fans were used only near working face to send fresh air. The application of the ventilation scheme in the construction met the requirements well.

- A nano-admixture was produced by grounding the zeolite to powder with a diameter less than $327.7 \times$ $10^{-9} \mathrm{~m}$. By adding this admixture into shotcrete, wet spraying of shotcrete at zones of rock burst and rich water was succeeded.

- In this project, various new materials, new machineries, new technologies, and new methods were developed. The application of these achievements succeeded the completion of the tunnel with a high quality within the contract period.

\section{References}

[1] S.G. Chen, Y. Zhao,H. Zhang, Analysis of large rock deformation under high in situ stress, In: Proceedings of 9th International Conference On Analysis Of Discontinuous Deformation, Singapore, 25-27 November, 2009: 367-372.
[2] S.G. Chen, H. Zhang, C.P. Yan, et al., The construction of the Jinping Auxiliary Tunnel in Karst rock, In: ISRM Regional Symposium EUROCK 2009, Rock Engineering in Difficult Ground Conditions-Soft Rocks and Karst, Dubrovnik, Cavtat, Croatia, 29-31 October, 2009: 617622.

[3] Chinese Railway 2nd Engineering Corporation Ltd., The construction technology of deep overburdened long tunnel in high pressure and rock water strata, 2008: 215 (in Chinese).

[4] J. Zhang, S. Ren, H. Jiang, et al., A study on major engineering geological issues for Jinping traffic tunnel, $A d$ vances in Science and Technology of Water Resources, 2006, 26(6): 66-70.

[5] C.P. Yan, J.S. Yang, S.G. Chen, An integrated geological prediction technology and its application at Fault F6 of Jinping traffic tunnel, Highway Tunnel, 2008, 61(1): 34-38 (in Chinese).

[6] W. Hu, J. Yang, S.G. Chen, The high pressure and big flow rate water inflow in Jinping traffic tunnel and its treatment, People's Yangtze River, 2008, 39(15): 83-86 (in Chinese).

[7] H. Zhang, S.G. Chen, A study on the simulation technology of sealing of groundwater with a high pressure, Jilin Water Resources, 2008(10): 1-4 (in Chinese).

[8] W. Hu, J. Yang, S.G. Chen, Rock burst analysis at Jinping traffic tunnel and its treatment, Chinese Journal of Underground Space and Engineering, 2008, 5(4): 834840 (in Chinese).

[9] J. Yang, A ventilation technology for a super long tunneling using jet fans and its application, Tunnel Construction, 2008, 28(4): 456-459 (in Chinese).

[10] H. Zhang, J. Yang, H. Gao, et al., A study on the construction ventilation of the Jinping traffic tunnel, Guangxi Water Resources and Hydropower Engineering, 2008(5): 11-13 (in Chinese).

[11] J. Yang, L. Xiang, S.G. Chen, Application of wet shotcrete spraying in rock burst zones of Western Jinping traffic tunnel, In: Proceedings of Chinese Roadway Tunnel Symposium, Xi' an, China, 28-29 October, 2007: 442-447. 